\title{
Investigating the Effects of COVID-19 Quarantine on Migraine: Data from the Italian National Headache Registry (RICe)
}

Marianna Delussi

Universita degli Studi di Bari Aldo Moro

Eleonora Gentile

Universita degli Studi di Bari Aldo Moro

Gianluca Coppola

Universita degli Studi di Roma La Sapienza Facolta di Medicina e Psicologia

Addolorata Maria Pia Prudenzano

Azienda Ospedale Policlinico Bari

Innocenzo Rainero

Universita degli Studi di Torino Scuola di Medicina

\section{Grazia Sances}

Fondazione Salvatore Maugeri Istituto Scientifico di Pavia Via Maugeri

Chiara Abagnale

Universita degli Studi di Roma La Sapienza Facolta di Medicina e Psicologia

Valeria Caponnetto

Universita degli Studi dell'Aquila

Francesco De Cesaris

Universita degli Studi di Firenze

Chiara Lupi

Universita degli Studi di Firenze

Ilaria Frattale

Universita degli Studi dell'Aquila

Elena Guaschino

Fondazione Salvatore Maugeri Istituto Scientifico di Pavia Via Maugeri

Andrea Marcinnò

Universita degli Studi di Torino Scuola di Medicina

Raffaele Ornello

Universita degli Studi dell'Aquila

Francesca Pistoia

Universita degli Studi dell'Aquila

Alessia Putortì

Fondazione Salvatore Maugeri Istituto Scientifico di Pavia Via Maugeri

Maria Elena Roca

Azienda Ospedale Policlinico Bari

\section{Fausto Roveta}

Universita degli Studi di Torino Scuola di Medicina

\section{Maria Trojano}

Universita degli Studi di Bari Aldo Moro

\section{Francesco Pierelli}

Universita degli Studi di Roma La Sapienza Facolta di Medicina e Psicologia

\section{Pierangelo Geppetti}

Universita degli Studi di Firenze

Simona Sacco

Universita degli Studi dell'Aquila

Marina De Tommaso ( $\square$ marina.detommaso@uniba.it)

Universita degli Studi di Bari Aldo Moro https://orcid.org/0000-0001-6567-5373

Research article

Keywords: COVID-19, migraine, lockdown 
Posted Date: July 1st, 2020

DOI: https://doi.org/10.21203/rs.3.rs-39228/v1

License: @ (i) This work is licensed under a Creative Commons Attribution 4.0 International License. Read Full License 


\begin{abstract}
BACKGROUND Previous studies during the SARS and Ebola pandemics have shown that quarantine is associated with several negative psychological effects. Although it is possible that quarantine for the current COVID-19 pandemic affects migraine burden, no information is currently available on this i AIM: In this study, we aimed: a) to explore the effect of quarantine on migraine frequency, severity and days with acute medication intake, and b) to evaluate whether migraine, changes in lifestyle, and emotions. were affected in a different manner in three geographic Italian areas with diverse COVID-19 diffusion, METHODS We interviewed patients included in the observational Italian registry of headache (Registro Italiano Cefalee, RICe), retrospectively collecting information on main headache features, lifestyles factors, emotions, individual infection status, and perception for COVID-19 for the two months before quarantine and during quarantine. Inclusion criteria were: age > 18; diagnosis of migraine without aura, migraine with aura, and chronic migraine; last inperson visit in the 3 months before the beginning of the quarantine. RESULTS A total of 433 migraine subjects agreed to be interviewed. We found an overall reduction in headache frequency and days with acute medication intake during the quarantine as compared to pre-quarantine. Reduction in headache frequency prevailed in patients reported more days of effective staying at home. Improvement was not evident in northern Italy. Disgust against viral infection corresponded to a reduced improvement in migraine parameters. CONCLUSIONS. Migraine patients showed a resilient behavior toward the pandemic distress. Disgust against the contagious disease, could increase migraine frequency. ssue.
\end{abstract}

\title{
Background
}

COVID-19 [21] was declared a global pandemic on March 11, 2020 by the World Health Organization. The diffusion of COVID-19 in Italy was markedly different, as northern Italy showed a much higher number of cases compared to central and southern Italy. On March 9, the Italian Government was the first in Europe to impose severe social distancing rules. At the time of the stay-at-home order, the Civil Protection Department of Italy recorded about 7375 total cases, with 366 deaths (http://www.salute.gov.it/imgs/C_17_pagineAree_5351_0_file.pdf). Social distancing and mitigation strategies [ 1,2,3] aim to defer major flows of patients and reduce the demand of hospital admissions, while safeguarding the most vulnerable subjects.

Studies related to the 2003 outbreak of severe respiratory acute syndrome (SARS) in China and Canada, or Ebola in 2014 in Africa, reported that quarantine was associated with several negative psychological effects, such as post-traumatic stress symptoms, confusion, and anger [4, 5]. Changes in social behavior and work activities, the unavailability of a public health system for routine medical management, and widespread fear of infection, could cause important psychosocial outcomes $[6,7,8]$, and thus significantly increase the burden of the disease. However, there are no data about the impact on migraine caused by psychosocial distress due to COVID-19 and long-term distancing measures.

In this study, we aimed: i. to explore the effect of quarantine on migraine frequency, severity, and days with acute medication intake, and; ii. to evaluate whether migraine was affected in a different manner in three geographic Italian areas with diverse COVID-19 diffusion and according to changes in lifestyle and emotions.

\section{Methods}

\section{Study population and design}

This observational cross-sectional study describes the impact of the COVID-19 pandemic and social distancing measures on headache features in migraine patients. It was conducted via a telephone structured interview in a sample of patients enrolled in the Italian Registry of Headache (Registro Italiano delle Cefalee, RICe). The RICe is an observational registry of the Italian Society for the Study of headaches (SISC), which records clinical data of consecutive patients aged $\geq 18$ years with headache who refer to the adhering Headache Centers. The present ancillary sub-study is based on data from 7 headache centers in northern (Pavia and Turin), central (Florence and Latina) and southern (Avezzano-L'Aquila and 2 headache centers in Bari) Italy. The 7 centers are located in geographical areas that had a markedly different impact of COVID-19 outbreak: higher in northern, medium in central, and lower in southern Italy (2020- http://www.protezionecivile.gov.it/attivita-rischi/rischio-sanitario/emergenze/coronavirus). For the present study, enrollment was limited to subjects with a diagnosis of migraine without aura, migraine with aura, and chronic migraine, according to the criteria of the International Classification of Headache Disorders, III edition [9], and with a last in-person visit within 3 months before the beginning of the quarantine.

\section{Telephone interviews and variables of interest}

Telephone interviews were done by the study investigators between March 30 and April 18. The interview was a web-supported questionnaire, completed in real time during the telephone call. The questionnaire was administered in Italian language (an English translation is provided as Supplementary Material). Variables of interest included frequency of headache expressed as average number of headache days per month, calculated during the 2 months preceding the quarantine (defined as pre-quarantine) and the time elapsed from the beginning of the quarantine (March 8, 2020 for Northern Italy, which was extended to the rest of Italy on March 10, 2020) to the day of the telephone interview (defined as quarantine).

Patients were asked to report the intensity of headache and the use of symptomatic drugs in the pre-quarantine and quarantine times, according to their headache diaries. Queries included: the number of the days of effective staying at home, current working condition, the level of risk contacts, individual infection, personal feeling on how COVID-19 affects migraine outcomes, or being a migraine sufferer as a possible risk factor for COVID-19, fear of being infected, possible changes of daily behaviors (food habits, alcohol consumption, and sleep quality) after social distancing, emotions in relation to pandemic emergency (fear, disgust, anxiety, sadness and happiness) in a scale from 0 (no emotion) to 10 (maximal emotion), subjective evaluation of mood change (worsening, no change, improvement) (see the questionnaire in the Supplementary Section).

\section{Study outcomes}

Page $3 / 11$ 
Primary outcome measures were the difference in headache frequency and intensity and days with acute medication intake between the pre-quarantine and quarantine. Secondary outcomes were changes in headache features, lifestyle habits, and emotions, according to geographic areas with diverse COVID-19 diffusion.

\section{Ethics}

Local Ethic Committees of each recruiting center approved the RICe registry; signed informed consent was requested to be included in the RICe registry.

\section{Statistical analysis}

In the absence of previous similar reports, and because of the descriptive nature of the study, the sample size was not calculated. Parametric distribution of data was evaluated by the Levene test for equality of variance. For the observation-period during quarantine varied across subjects, we normalized headache days for the effective period of observation (number of headache days/number of total days of observation $\mathrm{x} 30$ ). In a preliminary description of demographic and clinical data and general features of patients regarding the COVID-19 emergency, we used one-way ANOVA for quantitative variables and chi square test

for nominal variables for the comparison among different geographic areas. For evaluating primary and secondary outcomes measured during pre-quarantine vs. quarantine and in the three geographic areas, we used ANOVA for repeated measures. The effect of emotions and living behavior on headache features was evaluated by the same repeated measures ANOVA model, introducing nominal variables as factors and quantitative variables as covariates. A complete factorial ANOVA model type III included in IBM SPSS software ver 21 was used.

\section{Results}

\section{Demographic data, working status, living conditions, and daily habits}

A total of 433 migraine subjects agreed to be interviewed, while only 10 patients did not give their consent. The mean interval that elapsed from the beginning of the quarantine and the time of the interview was $31.9 \pm 4.5$ days (20-40 days), without significant differences across participating centers. Demographic characteristics of enrolled patients are presented in Table 1. Patients in northern Italy were older than in central and southern Italy; education level was higher in northern and southern Italy (Table 1). Days spent at home after start of quarantine were fewer in northern Italy as compared to the other two areas (Table 1). In northern Italy, less patients were unemployed, and more patients lived in urban areas, whereas in Central Italy fewer patients were able to telecommute (Table 1). 
Table 1

Baseline characteristics of the included subjects

\begin{tabular}{|c|c|c|c|c|c|c|}
\hline & $\begin{array}{l}\text { All }(n= \\
433)\end{array}$ & $\begin{array}{l}\text { North }(n= \\
105)\end{array}$ & $\begin{array}{l}\text { Center }(n= \\
101)\end{array}$ & $\begin{array}{l}\text { South }(n= \\
227)\end{array}$ & $\begin{array}{l}\text { Statistic } \\
\text { Comparison }\end{array}$ & $P$ value \\
\hline Gender, n (\%) & & & & & $x^{2} 3.7$ & NS \\
\hline Female & $333(76.9)$ & 77 (73.3) & 73 (72.3) & $183(80.6)$ & & \\
\hline Male & $100(23.1)$ & $28(26.7)$ & $28(27.7)$ & $44(19.4)$ & & \\
\hline Age (years), mean \pm SE & $\begin{array}{l}43.97 \pm \\
0.63\end{array}$ & $47.24 \pm 1.17$ & $42.00 \pm 1.51$ & $43.36 \pm 0.71$ & F 4.9 & $0.008^{*}$ \\
\hline $\mathrm{BMI}$, mean $\pm \mathrm{SE}$ & $\begin{array}{l}24.1 \pm \\
0.002\end{array}$ & $24 \pm 0.004$ & $24 \pm 0.005$ & $24 \pm 0.003$ & F 0.12 & 0.880 \\
\hline \multicolumn{7}{|l|}{ Education years, n (\%) } \\
\hline $0-5$ & $16(3.7)$ & $2(1.9)$ & $4(4.0)$ & $10(4.4)$ & & \\
\hline $6-8$ & $84(19.4)$ & $29(27.6)$ & $21(20.8)$ & $34(15.0)$ & & \\
\hline $9-13$ & $175(40.4)$ & 33 (31.4) & $52(51.5)$ & $90(39.6)$ & & \\
\hline$>13$ & $158(36.5)$ & $41(39.0)$ & $24(23.8)$ & $93(41.0)$ & $\chi^{2} 18.8$ & 0.005 \\
\hline $\begin{array}{l}\text { Days of staying at home for quarantine } \\
\text { mean } \pm \text { SE }\end{array}$ & $\begin{array}{l}29.27 \pm \\
0.58\end{array}$ & $24.6 \pm 1.98$ & $32.26 \pm 2.00$ & $31.56 \pm 1.35$ & F 4.9 & $0.008^{\star \star}$ \\
\hline \multicolumn{7}{|l|}{ Home place, n (\%) } \\
\hline Countryside & $76(17.8)$ & $2(1.9)$ & 40 (39.6) & $34(15.0)$ & & \\
\hline City & $183(42.3)$ & $58(55.2)$ & $32(31.7)$ & $93(41.0)$ & & \\
\hline Small town & $174(40.2)$ & $45(42.9)$ & $29(28.7)$ & $100(44.1)$ & $\chi^{2} 54.7$ & $\begin{array}{l}<.0001 \\
0\end{array}$ \\
\hline $\begin{array}{l}\text { No. of cohabiting family members during social distancing, } \\
\text { mean } \pm \mathrm{SE}\end{array}$ & $\begin{array}{l}2.32 \pm \\
0.13\end{array}$ & $2.34 \pm 0.26$ & $2.36 \pm 0.2$ & $2.26 \pm 0.17$ & F 0.49 & 0.95 \\
\hline \multicolumn{7}{|l|}{ Work, n (\%) } \\
\hline Unemployed & $208(48.0)$ & $38(36.2)$ & $58(57.4)$ & $112(49.3)$ & & \\
\hline Employed & $225(52.0)$ & $67(63.8)$ & $43(42.6)$ & $115(50.7)$ & $\chi^{2} 9.6$ & 0.008 \\
\hline \multicolumn{7}{|l|}{ Employment, n (\%) } \\
\hline Telecommuting & $89(20.6)$ & $26(24.8)$ & $12(11.9)$ & $51(22.5)$ & & \\
\hline Regular working & $48(11.1)$ & $25(23.8)$ & $19(18.8)$ & $44(19.4)$ & & \\
\hline Lost job & $88(20.3)$ & $16(15.2)$ & $12(11.9)$ & $20(8.8)$ & $\chi^{2} 16.5$ & 0.036 \\
\hline \multicolumn{7}{|c|}{ BMI indicates body mass index; NS, not significant; SE, standard error } \\
\hline \multicolumn{7}{|l|}{ F: One-way ANOVA test } \\
\hline \multicolumn{7}{|l|}{$\chi^{2}:$ Chi square } \\
\hline \multicolumn{7}{|l|}{${ }^{*} \mathrm{P}<0.01$ (North vs Center) post hoc Bonferroni test } \\
\hline$\star \star P<0.05$ (North vs Center vs South) post hoc Bonferroni tes & & & & & & \\
\hline
\end{tabular}

Table 1.

Quarantine was not associated with changes in food intake, sleep, and alcohol assumption (Table 2). 
Table 2

Reported change in daily habits during social distancing in the included patients according to geographic areas

\begin{tabular}{|c|c|c|c|c|c|c|}
\hline & All $(n=433)$ & North $(n=105)$ & Center $(n=101)$ & South $(n=227)$ & $x^{2}$ & $P$ value \\
\hline Food intake, n (\%) & & & & & 0.6 & 0.67 \\
\hline Increased & $67(15.5)$ & $18(17.1)$ & $14(13.9)$ & $35(15.4)$ & & \\
\hline Reduced & $153(35.3)$ & $32(30.5)$ & $32(31.7)$ & $89(39.2)$ & & \\
\hline Unchanged & $213(49.2)$ & $55(52.4)$ & $55(54.5)$ & $103(45.4)$ & & \\
\hline Alcohol consumption, n (\%) & & & & & 0.89 & 0.89 \\
\hline Reduced & $85(19.6)$ & $20(19.0)$ & $25(24.8)$ & $40(17.6)$ & & \\
\hline Increased & $13(3.0)$ & $5(4.8)$ & $2(2.0)$ & $6(2.6)$ & & \\
\hline Unchanged & $344(79.4)$ & $89(84.8)$ & $74(73.3)$ & $181(79.7)$ & & \\
\hline Sleep quality, n (\%) & & & & & 0.68 & 0.6 \\
\hline Improved & $157(36.3)$ & $39(37.1)$ & $37(36.6)$ & $81(35.7)$ & & \\
\hline Worsened & $45(10.4)$ & $8(7.6)$ & $11(10.9)$ & $26(11.5)$ & & \\
\hline Unchanged & $229(52.9)$ & $58(55.2)$ & $53(52.5)$ & $118(52.0)$ & & \\
\hline
\end{tabular}

Table 2 .

\section{Effects of quarantine on migraine, emotions, and lifestyles}

Migraine subjects living in southern Italy experienced more anger and reduced happiness, as compared to patients in northern Italy (Table 3). Patients living in central Italy reported more sadness compared to patients in northern Italy (Table 3).

Table 3

Reported intensity of emotions related to the COVID-19 emergency on a 0-10 scale according to geographic areas.

\begin{tabular}{|lllllll|}
\hline \multicolumn{7}{|c|}{ Data are in mean \pm standard error. } \\
\hline Anger & $3.83 \pm 0.27$ & $4.15 \pm 0.27$ & $4.81 \pm 0.18$ & 5,2 & 0.01 & $<0.01$ (South vs North) \\
\hline Disgust & $3.63 \pm 0.26$ & $3.39 \pm 0.27$ & $3.18 \pm 0.18$ & 0.3 & 0.70 & - \\
\hline Fear & $5.54 \pm 0.27$ & $5.71 \pm 0.28$ & $5.81 \pm 0.19$ & 0.3 & 0.71 & - \\
\hline Anxiety & $5.65 \pm 0.28$ & $5.97 \pm 0.28$ & $5.72 \pm 0.19$ & 0.4 & 0.68 & - \\
\hline Sadness & $4.70 \pm 0.27$ & $5.65 \pm 0.28$ & $5.40 \pm 0.19$ & 3.3 & 0.04 & $<0.01$ (Center vs North) \\
Happiness & $5.39 \pm 0.23$ & $4.67 \pm 0.23$ & $4.24 \pm 0.16$ & 8.7 & $<0.01$ & $<0.001$ (South vs North) \\
\hline
\end{tabular}

Table 3.

During quarantine, 177 subjects (55.1\%) reported worsening, 42 (13.1\%) no change, and 102 (31,8\%) improvement of mood. In northern Italy, mood was unchanged in $57 \%$ of subjects and worsened in $31 \%$, while in southern and central Italy mood was unchanged in $42 \%$ of subjects and worsened in $43 \%$.

Most patients subjectively reported that their migraines did not change since the start of quarantine (supplementary Table 1) and did not consider migraine as a facilitating factor for COVID-19 infection, although this opinion did prevail in southern Italy.

Headache frequency in pre-quarantine was similar among the three different geographic areas. Preventive treatments for migraine were used by 289 (66.74\%) of the total number of patients. Headache frequency at baseline did not differ according to the use or not-use of preventive medications (Supplemental Table 2). A reduction in the number of days with headache, days with acute medication intake, and of migraine intensity, was observed during quarantine as compared to pre-quarantine (Fig. 1;Table 4). 
Table 4

Comparison of headache features before and during lockdown period in the included patients. Result of repeated measures ANOVA are reported. Data are repo

\begin{tabular}{|c|c|c|c|c|c|c|c|c|c|c|c|c|}
\hline & \multicolumn{4}{|c|}{ All $(n=433)$} & \multicolumn{2}{|c|}{ North $(n=105)$} & \multicolumn{2}{|c|}{ Center $(n=101)$} & \multicolumn{2}{|c|}{ South $(n=227)$} & \multirow[b]{2}{*}{$\begin{array}{l}\text { F(geographic } \\
\text { area) }\end{array}$} & \multirow[b]{2}{*}{$\begin{array}{l}\mathrm{P} \\
\text { value }\end{array}$} \\
\hline & Before & During & $\begin{array}{l}\text { F } \\
\text { (before } \\
\text { vs } \\
\text { during) }\end{array}$ & $\begin{array}{l}\mathrm{P} \\
\text { value }\end{array}$ & Before & During & Before & During & Before & During & & \\
\hline $\begin{array}{l}\text { Monthly } \\
\text { headache } \\
\text { days }\end{array}$ & $\begin{array}{l}9.42 \pm \\
0.43\end{array}$ & $\begin{array}{l}8.28 \pm \\
0.41\end{array}$ & 15.5 & $<.001$ & $\begin{array}{l}10.57 \\
\pm 0.81\end{array}$ & $\begin{array}{l}11.03 \\
\pm 0.78\end{array}$ & $\begin{array}{l}8.19 \pm \\
0.84\end{array}$ & $\begin{array}{l}6.02 \pm \\
0.80\end{array}$ & $\begin{array}{l}9.50 \pm \\
0.56\end{array}$ & $\begin{array}{l}7.78 \pm \\
0.53\end{array}$ & 6 & 0.003 \\
\hline $\begin{array}{l}\text { Acute } \\
\text { medication } \\
\text { days }\end{array}$ & $\begin{array}{l}8.32 \pm \\
0.51\end{array}$ & $\begin{array}{l}7.19 \pm \\
0.54\end{array}$ & 7 & 0.008 & $\begin{array}{l}10.21 \\
\pm 0.96\end{array}$ & $\begin{array}{l}10.79 \\
\pm 1.02\end{array}$ & $\begin{array}{l}7.29 \pm \\
0.98\end{array}$ & $\begin{array}{l}5.07 \pm \\
1.04\end{array}$ & $\begin{array}{l}7.46 \pm \\
0.65\end{array}$ & $\begin{array}{l}5.70 \pm \\
0.69\end{array}$ & 3.6 & 0.027 \\
\hline $\begin{array}{l}\text { Headache } \\
\text { intensity }\end{array}$ & $\begin{array}{l}6.93 \pm \\
0.10\end{array}$ & $\begin{array}{l}6.71 \pm \\
0.11\end{array}$ & 6 & 0.014 & $\begin{array}{l}6.57 \pm \\
0.19\end{array}$ & $\begin{array}{l}6.59 \pm \\
0.21\end{array}$ & $\begin{array}{l}7.25 \pm \\
0.21\end{array}$ & $\begin{array}{l}7.03 \pm \\
0.22\end{array}$ & $\begin{array}{l}6.96 \pm \\
0.21\end{array}$ & $\begin{array}{l}6.50 \pm \\
0.14\end{array}$ & 3 & 0.05 \\
\hline
\end{tabular}

NS indicates not significant

Figure 1

Table 4.

However, findings were unevenly distributed across the three areas. In fact, in northern Italy improvements were not observed. Moreover, discontinuation of preventive treatment for any reason, including adverse events or difficulties in dispensing drugs, prevailed in patients living in southern Italy (Supplementary Table 2). Changes in headache parameters were also similar among patients living in different urban areas and with different levels of education. Alcohol use, smoking, eating, and subjective perception of sleep quality did not affect headache frequency and intensity, use of symptomatic drugs, or working situation.

We found a correlation between reduction in headache frequency and increase in the number of days of quarantine (ANOVA with repeated measures with days of social distancing as covariate $\mathrm{F} 37.07 \mathrm{p}<0.0001$ ) (Fig. 2).

Figure 2

There was a significant relationship between disgust against COVID-19 infection and increase in headache frequency (repeated measures ANOVA with disgust as covariate F 6.43 p 0.004; Fig. 2b). Patients reporting mood improvement showed reduced headache frequency (repeated measures ANOVA with mood perception as factor: $F 5.43$ p 0.001), independently from the region of residence (mood perception $x$ area of residence $F 0.23 p 0.91$ ). However, the Bonferroni test among the different mood perceptions was not significant. Patients who subjectively reported a worsening of their migraine showed an objective increase in headache frequency (Repeated measures ANOVA with subjective impression of migraine severity as factor: $\mathrm{F} 35.58 \mathrm{p}<0.0001$ : Bonferroni test: got worse vs improved $p$ < 0.01). Patients feeling migraine as a facilitating factor for infection showed a slight tendency toward frequency increase (ANOVA with perception of migraine as risk factor : F 3.59 p 0.012 Bonferroni test: n.s.).

\section{COVID-19 infection in migraine sample}

Among the enrolled patients, only 5 reported to have been infected by SARS-CoV-2 (Table 5 ). These 5 patients did not report any substantial changes in their migraine features after knowing that they were infected.

Table 5

Characteristics of migraine patients positive to SARS-CoV-2 infection. Changes refer to quarantine measures compared with the two previous months.

\begin{tabular}{|lllllllll|}
\hline & Age & Sex & $\begin{array}{l}\text { Geographic } \\
\text { area }\end{array}$ & Symptomatic & $\begin{array}{l}\text { CoVID-19 } \\
\text { Outcome }\end{array}$ & $\begin{array}{l}\text { Migraine frequency } \\
\text { change (\%) }\end{array}$ & $\begin{array}{l}\text { Mean intensity } \\
\text { change (points) }\end{array}$ \\
\hline $\begin{array}{l}\text { Patient } \\
1\end{array}$ & 22 & F & South & No & - & -18 & 0.38 & $\begin{array}{l}\text { Change in use of } \\
\text { symptomatic drugs (\%) }\end{array}$ \\
\hline $\begin{array}{l}\text { Patient } \\
2\end{array}$ & 56 & $F$ & North & No & - & -20 & 1 & -75 \\
\hline $\begin{array}{l}\text { Patient } \\
3\end{array}$ & 47 & F & South & Yes & $\begin{array}{l}\text { Under } \\
\text { treatment }\end{array}$ & -20 & 0.88 & 0 \\
\hline $\begin{array}{l}\text { Patient } \\
4\end{array}$ & 44 & F & North & Yes & Recovered & -40 & 1 & -32 \\
\hline $\begin{array}{l}\text { Patient } \\
5\end{array}$ & 46 & F & North & Yes & $\begin{array}{l}\text { Under } \\
\text { treatment }\end{array}$ & -30 & 0.5 & 0 \\
\hline
\end{tabular}

Table 5. 


\section{Discussion}

The results of the present study outline a resilient behavior of migraine subjects in response to quarantine for the COVID-19 pandemic, given that headache frequency, days with acute medication intake, and headache intensity improved after social distancing. The amelioration was less evident in the geographic area where the frequency of prevalence of COVID-19 was highest and appeared to be related to the length of the stay-at-home order. Disgust toward infection corresponded to an attenuation of headache improvement.

\section{Demographic and clinical characteristics}

The interview was conducted on migraine patients previously enrolled in the RICe, which guaranteed a strong accuracy of demographic and clinical data, previously recorded, as compared to a telephone interview with previously unknown subjects [10]. Patients were stratified according to Italian geographic areas with different epidemic impacts. Demographic data were quite homogeneous among patients enrolled in the participating headache centers, except for the difference in employment rate, which substantially reproduces what the Italian Statistic Institute reports (http://dati.istat.it/Index.aspx? lang=en\&SubSessionld=89159293-7a2c-4335-a295-f58732d3366d). Frequency of migraine before the social distancing and consequent use of preventive treatments were also similar among different Italian areas.

\section{Social distancing}

Social distancing is recommended as a preventive measure to reduce the spreading of epidemics [1, 3, 11]. The limited number of days of stay-at-home order of migraine patients in northern Italy seems noteworthy. Statistical data on social distancing behaviors of people living in regions with different epidemic impact are not currently available, and these observations are beyond the principal aim of the present study. Despite the limited number of enrolled patients, the present data seems to indicate a paradoxically reduced number of days of stay-at-home order in areas with higher viral diffusion.

The emotional reaction towards the pandemic emergency prevailed in southern and central Italy. An increased expression of anger in southern Italy and of sadness in central Italy, compared to northern Italy, were observed. We hypothesize that in northern Italy a reduced negative emotive reaction against the pandemic could be justified by the need to maintain normal habits, thus potentially facilitating viral diffusion. These results confirm recent data recorded in almost 9000 Italian citizens during the COVID-19 quarantine, showing a higher negative emotional impact of pandemic in regions less affected by the epidemic [12].

\section{Migraine and pandemic emergency}

The reasons for the improvement of headache frequency, intensity, and days with acute medication intake, especially in migraine patients reporting more stayat-home days, merit further consideration. A higher viral diffusion might have contributed to the onset of stress-related disorders [8, 13], thereby worsening migraine [14]. On the other hand, development of a resilient behavior in response to COVID-19 [15] might be expressed also by migraine patients, thus ameliorating migraine features. In fact, resilience is generally associated with better outcome in patients with chronic pain [15]. In a previous large, global, cross-sectional study, patients with frequent migraines showed greater resilience in response to negative events, such as treatment failures [16]. Psychological features of migraine patients, underlying a favorable outcome under the current dramatic pandemic, were not recorded in previous visits of the RICe database. However, this item could be a subject for further studies in a possible scenario of pandemic persistence [17]. No correlation between the emotional impact of the pandemic and its effect on migraine features was found. However, the perception that migraine could facilitate COVID-19 infection, possibly causing additional stress, negatively affected headache frequency. The subjective impression of migraine worsening with pandemic emergency slightly prevailed in northern Italy, where patients showed worsened headache frequency as compared to central and southern Italy. The pandemic emergency was not associated with sleep disruption in our migraine sample, an effect attributable to the resilient reaction.

The improvement of headache parameters was not associated with working activity and lifestyle habits, or the slight and not relevant changes in food and alcohol consumption during the quarantine. However, it was correlated with the number of days of stay-at-home order $[18,19]$. The resilient behavior against migraine worsening for pandemic distress could thus be enhanced during social distancing. This result could be taken into consideration for the social management of public health during pandemics [3]. The expression of disgust was slightly associated with migraine frequency increase. Disgust is an emotional response of rejection or revulsion to something potentially contagious or offensive [20]. It is a system that evolved to motivate infectious disease avoidance and combat the behavioral causes of infectious and chronic disease, such as pandemic flu [21]. While it could help in assessing avoidance behavior during pandemic infections, it is a cause of distress [21], which could have a negative impact on migraine frequency and attenuate the resilient reaction.

\section{COVID-19 infection in migraine sample}

Although the present study was not designed to assess the frequency of infection in a migraine population, because of the relatively small sample, we found 5 out of 433 migraine patients positive for the SARS-CoV-2 infection (1,38\%). At the time data was collected, there were about 185.000 infected people in the general Italian population $(0,3 \%)$, with a slight prevalence in males $(51,7 \%)$ and a median age of 62 years. (Italian Health System and Civil Protection report http://www.protezionecivile.gov.it/attivita-rischi/rischio-sanitario/emergenze/coronavirus). However, the percent rate of asymptomatic persons among the general population is an unresolved issue, so present data do not enable any type of speculation about prevalence of SARS-CoV-2 infection in migraine patients.

\section{Study limitations}

Major limitations of the present study are the limited number of patients and the uneven distribution of the sample between the different geographic areas. The limitations were due to the restricted time window of the study, determined by the timing of the restrictive measures (phase I), decided by the Italian Government, and to the fact that enrolled patients were those who have previously given informed consent to the RICe study. Additional limitations are the

Page 8/11 
poor reliability of headache frequency reports during pandemic emergency and the short time of evaluation of migraine features during quarantine (1 month on average).

\section{Conclusions}

Overall, we found that migraine patients showed a resilient behavior against the pandemic distress, with a reduction in migraine severity indices. Maintenance of habitual lifestyles during social distancing further supports the role of resilience, which was less evident in people with a limited number of days of stay-athome order, as in northern Italy. The reduction in migraine burden during quarantine could compensate for the poor quality patient care via remote tools, such as telemedicine visits [8], required to minimize the access of patients to headache centers during the peak of the pandemic.

\section{Abbreviations}

RICe

Registro Italiano Cefalee- Italian Headache Registry

SISC

Società Italiana Studio Cefalee-Italian Society for Headache Study

\section{Declarations}

\section{Ethics approval and consent to participate}

Local Ethic Committees of each recruiting center approved the RICe registry; signed informed consent was requested to be included in the RICe registry.

\section{Consent for publication}

Not applicable

Availability of data and materials

The datasets used and/or analysed during the current study are available from the corresponding author on reasonable request.

\section{Competing interests}

The authors declare that they have no competing interests

\section{Marianna Delussi and Eleonora Gentile equally contributed}

study design, interview preparation, patient selection and study coordination

\section{Pierangelo Geppetti and Simona Sacco}

manuscript preparation, data analysis, manuscript editing

\section{Raffaele Ornello}

study design, statistical analysis

Chiara Abagnale, Valeria Caponnetto, Francesco De Cesaris, llaria Frattale, Elena Guaschino, Andrea Marcinnò, Francesca Pistoia, Alessia Putortì, Maria Elena Roca, Fausto Roveta

patient selection, manuscript editing and preparation, telephone interviews

Chiara Lupi

RICe data, patient selection, telephone interviews

\section{Conflict of interest}

No author declares conflict of interest

\section{Funding}


No funding sources were provided.

\section{Acknowledgements}

The study was promoted by the Italian Society for Headache Study (SISC).

\section{References}

1. Anderson RM, Heesterbeek H, Klinkenberg D, Hollingsworth TD. How will country-based mitigation measures influence the course of the COVID-19 epidemic? Lancet 2020; 395: 931-934.

2. Nussbaumer-Streit B, Mayr V, Dobrescu Al, Chapman A, Persad E, Klerings I, et al. Quarantine alone or in combination with other public health measures to control COVID-19: a rapid review. Cochrane Database Syst Rev 2020 Apr 8;4:CD013574. doi: 10.1002/1465185

3. Parodi SM, Liu VX. From Containment to Mitigation of COVID-19 in the US. JAMA - J Am Med Assoc 2020 1001/jama.2020.3882

4. Brooks SK, Webster RK, Smith LE, Woodland L, Wessely S, Greenberg N, et al. The psychological impact of quarantine and how to reduce it: rapid review of the evidence. Lancet 2020;395:912-20.

5. Hawryluck L, Gold WL, Robinson S, Pogorski S, Galea S, Styra R. SARS control and psychological effects of quarantine, Toronto, Canada. Emerg Infect Dis 2004;10:1206-12.

6. Person B, Sy F, Holton K, Govert B, Liang A, National Center for Inectious Diseases/SARS Community Outreach Team. Fear and stigma: the epidemic within the SARS outbreak. Emerg Infect Dis 2004; 10: 358-63.

7. Shultz JM, Cooper JL, Baingana F, Oquendo MA, Espinel Z, Althouse BM, et al. The Role of Fear-Related Behaviors in the 2013-2016 West Africa Ebola Virus Disease Outbreak. Curr Psychiatry Rep 2016; 18

8. Szperka CL, Ailani J, Barmherzig R, Klein BC, Minen MT, Halker Singh RB, et al. Migraine Care in the Era of COVID-19: Clinical Pearls and Plea to Insurers. Headache 2020

9. Headache Classification Committee of the International Headache Society (IHS) The International Classification of Headache Disorders,3rd edition Cephalalgia 2018; 38(1) 1-211

10. Potter R, Hee SW, Griffiths F, Dodd K, Hoverd E, Underwood M, et al. Development and validation of a telephone classification interview for common chronic headache disorders. J Headache Pain 2019; 20

11. Giordano G, Blanchini F, Bruno R, Colaneri P, Di Filippo A, Di Matteo A, et al. Modelling the COVID-19 epidemic and implementation of population-wide interventions in Italy. Nat Med 2020: 1-6.

12. Motta Zanin G, Gentile E, Parisi A, Spasiano D. A Preliminary Evaluation of the Public Risk Perception Related to the COVID-19 Health Emergency in Italy. Int J Environ Res Public Health 2020; 17: 3024

13. Horesh D, Brown AD. Traumatic stress in the age of COVID-19: A call to close critical gaps and adapt to new realities. Psychol Trauma 2020; 12 : $331-335$.

14. Peterlin BL, Katsnelson MJ, Calhoun AH. The associations between migraine, unipolar psychiatric comorbidities, and stress-related disorders and the role of estrogen. Curr Pain Headache Rep 2009; 13: 404-12.

15. France CR, Ysidron DW, Slepian PM, French DJ, Evans RT. Pain resilience and catastrophizing combine to predict functional restoration program outcomes. [Internet]. Heal Psychol 2020[cited 2020 May 2] Available from: http://doi.apa.org/getdoi.cfm?doi=10.1037/hea0000877

16. Martelletti P, Schwedt TJ, Lanteri-Minet M, Quintana R, Carboni V, Diener HC, et al. My Migraine Voice survey: A global study of disease burden among individuals with migraine for whom preventive treatments have failed. J Headache Pain 2018; 19

17. Lipsitch M, Swerdlow DL, Finelli L. Defining the epidemiology of Covid-19 - Studies needed. N Engl J Med 2020; 382: 1194-1196.

18. Santos IS, Griep RH, Alves MGM, Goulart AC, Lotufo PA, Barreto SM, et al. Job stress is associated with migraine in current workers: The Brazilian Longitudinal Study of Adult Health (ELSA-Brasil). Eur J Pain (United Kingdom) 2014; 18: 1290-1297.

19. Wilkins K, Beaudet MP. Work stress and health. Heal reports 1998; 10: 47-62 (ENG); 49-66 (FRE).

20. Badour CL, Feldner MT. The Role of Disgust in Postraumatic Stress. J Exp Psychopathol 2018; 9: pr.032813.

21. Curtis V. Why disgust matters. Philos Trans R Soc Lond B Biol Sci 2011; 366: 3478-90.

\section{Figures}



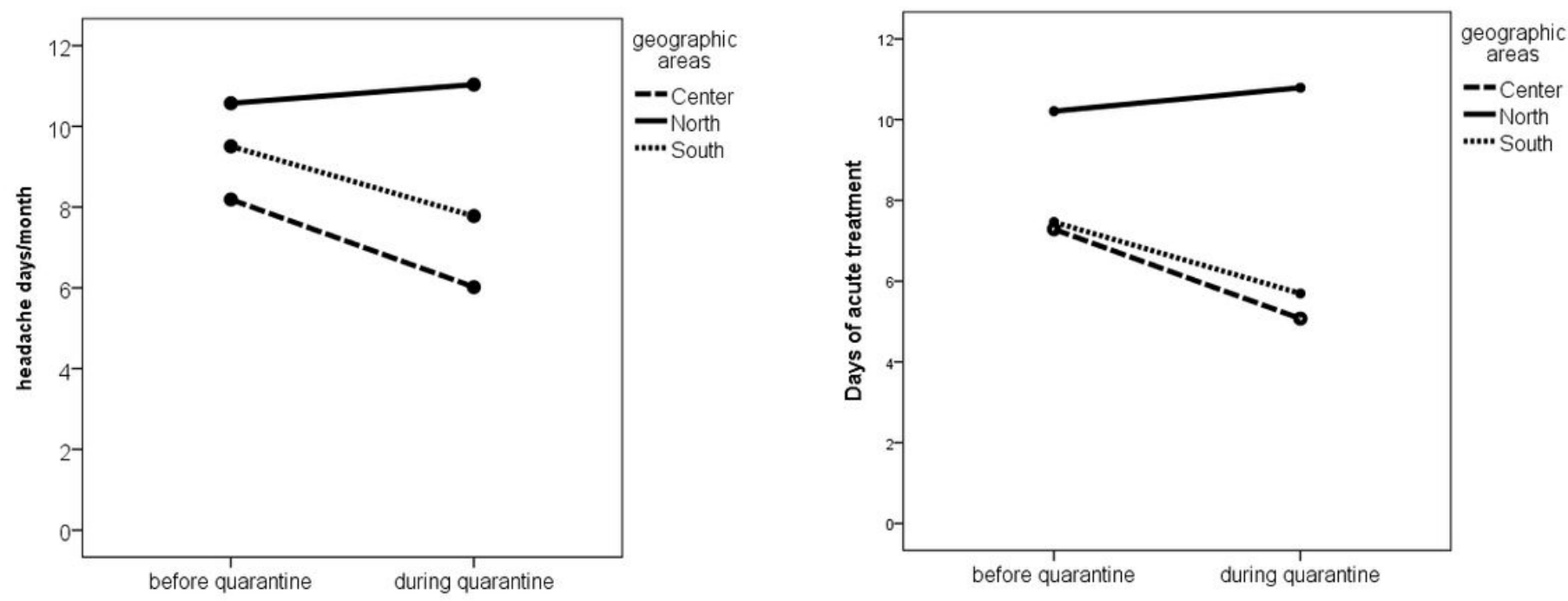

Figure 1

Change of days with headache and acute medication intake in migraine patients according to three geographic areas.

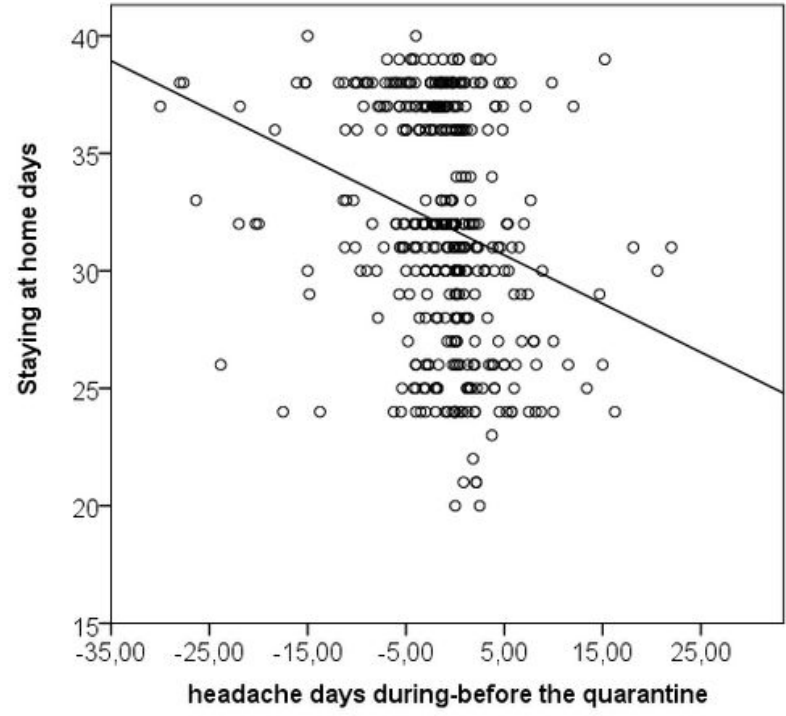

a)

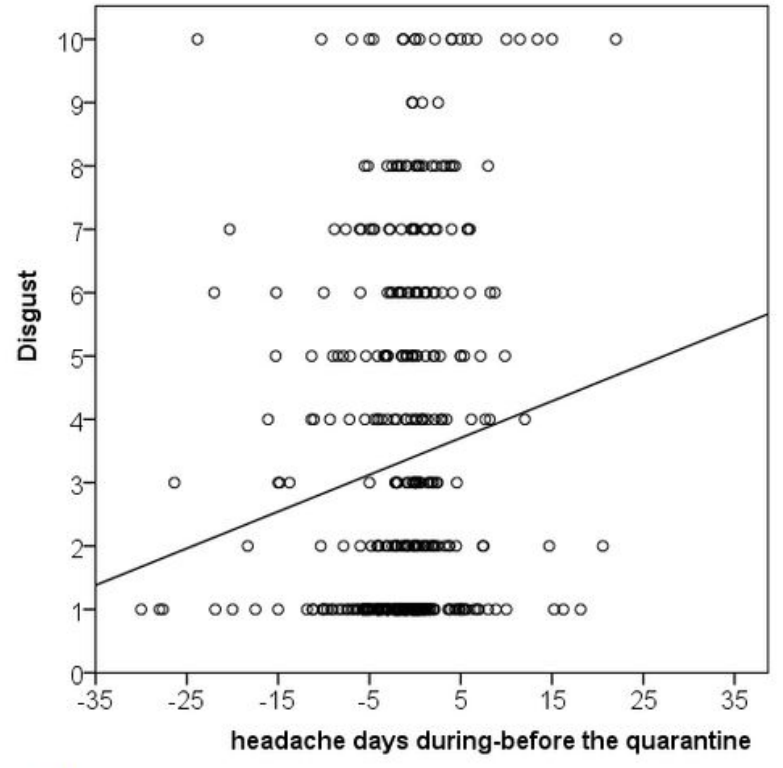

b)

Figure 2

Relationship between difference of normalized headache days after and before the date of official rules of social distancing, and a) days of effective stay-athome order; b) disgust reported by patients.

\section{Supplementary Files}

This is a list of supplementary files associated with this preprint. Click to download.

- SupplementalTables.docx 